\title{
DA UNIVERSIDADE AO MUNDO DO TRABALHO: PRÁTICA DOCENTE NA FORMAÇÃO DE FUTUROS GESTORES
}

\section{FROM THE UNIVERSITY TO THE WORLD OF WORK: TEACHING PRACTICE IN THE FORMATION OF FUTURE MANAGERS}

\author{
Corina Alves Farinha ${ }^{1}$, Patrícia Rosânia de Sá Moura ${ }^{1}$ \\ ${ }^{1}$ Universidade do Estado de Minas Gerais, Campi CBH, Faculdade de Políticas Públicas, Brasil, \\ corina.farinha@gmail.com, e mourapatricia72@hotmail.com
}

\author{
ARTICLE INFO \\ Article history: \\ Received 2020-01-16 \\ Accepted 2020-06-20 \\ Available online $2020-06-20$
}

Palavras-chave: Formação profissional. Mundo do trabalho. Diversidade sexual.

Keywords: Professional qualification. World of work. Sexual diversity.

RESUMO. A diversidade constitui, na atualidade, um tema bastante difundido no âmbito das organizações, contudo ainda não se tem clareza das práticas e políticas da gestão da diversidade, sobretudo quando se trata do público LGTB. Em outros termos, de que modo esse público vem sendo tratado no ambiente de trabalho? Sendo assim, essa pesquisa procura analisar a formação profissional de 120 futuros gestores para o mundo do trabalho em termos de diversidade sexual. 0 objetivo consistiu em identificar em que medida os conteúdos das disciplinas de Políticas Públicas, Direitos Humanos e Gestão de Pessoas são capazes de sensibilizar os estudantes sobre as atitudes discriminatórias e/ou preconceituosas com pessoas LGBT no ambiente organizacional, o quanto essas pessoas são muitas vezes excluídas desse meio. Trata-se de uma pesquisa quantitativa de natureza exploratória e descritiva, por meio de estudo de caso. Para coleta de dados utilizou-se do método investigativo de problematização da realidade e solução de problemas. Os resultados indicam que os conteúdos das disciplinas, componentes do currículo da instituição pesquisada, se revelam instrumentos importantes para ampliar ou modificar a percepção dos estudantes quanto a atitudes discriminatórias.

ABSTRACT. Diversity is nowadays a very widespread issue in organizations, but the practices and policies of diversity management are not yet clear, especially when it comes to the LGBT public. In other words, how has this audience been treated in the workplace? Thus, this research seeks to analyze the professional training of 120 future managers for the world of work in terms of sexual diversity. The objective was to identify to what extent the contents of the Public Policy, Human Rights and People Management disciplines are able to sensitize students about discriminatory and / or prejudiced attitudes towards LGBT people in the organizational environment, how often these people are excluded from that environment. It is a quantitative research of exploratory and descriptive nature, through a case study. To collect data was used the investigative method of problematization of reality and solution of problems. The results indicate that the contents of the disciplines, components of the curriculum of the research institution, are important tools to broaden or modify the students' perception of discriminatory attitudes. 


\section{Introdução}

Este trabalho é fruto do Projeto de Pesquisa intitulado Desafios e perspectivas para a gestão de pessoas na inclusão da diversidade sexual ï Edital 08/2015 PAPq, Programa de Apoio à Pesquisa, fomentado pela UEMG - Universidade do Estado de Minas Gerais, Campi $\mathrm{BH}$, em que foram discutidos aspectos referentes ao processo de recrutamento e seleção de candidatos LGBT para o mundo do trabalho. O projeto visou elencar desafios e perspectivas às pessoas LGBT ï Lésbicas, gays, bissexuais e transexuais no mundo da escola e do trabalho. Pretendeu-se contribuir para o entendimento da temática visando reduzir ações prejudiciais às pessoas LGBT. Foram coletados dados junto a três empresas de recrutamento e seleção de Belo Horizonte, MG e, para compreender a visão de um grupo de discentes sobre o tema, foi aplicado um questionário fechado, numa escala de Likert, 5 pontos. O referencial teórico situou-se em políticas públicas governamentais, das Organizações das Nações Unidas entre outras publicações da área.

Neste trabalho são apresentados os resultados referentes à aplicação do questionário. O objetivo foi desenvolver competência em gestão de pessoas de futuros gestores por meio da metodologia de ensino: problematização da realidade e a solução de problema. Os dados interpretados possibilitaram mapear a percepção dos alunos sobre a inclusão da diversidade sexual no mundo do trabalho. A opção metodológica de ensino e aprendizagem apoia-se na concepção de educação libertadora e problematizadora e do papel do educador de Freire (2000). A solução de problemas implica na participação ativa e no diálogo constante entre professor e aluno. A aprendizagem é concebida como a resposta do aluno ao desafio de uma situação-problema (BORDENAVE, PEREIRA, 2012).

Participaram da pesquisa 120 discentes, cuja autorização foi coletada por escrito. Salienta-se: a atividade não foi pontuada e aqueles que não quiseram responder 0 questionário, puderam contribuir nas atividades e discussões em sala. Os sujeitos da pesquisa foram graduandos dos Cursos de Tecnologia em Gestão de Recursos Humanos, Processos Gerenciais e Gestão Pública da Faculdade de Políticas Públicas ï Campi Belo Horizonte ï Universidade do Estado de Minas Gerais e responderam a seguinte questãoproblema: r̃ Sou gestor (a) em uma organização. Num processo seletivo tenho uma vaga e dois candidatos com perfil adequado. $\mathrm{Na}$ entrevista percebo, de alguma forma, que um deles é heterossexual e o outro LGBT. Qual candidato eu admito?ò Constatou-se que os alunos adotaram a perspectiva do princípio da diversidade sexual sugestivo da aplicação da justiça social preconizada pelas políticas públicas norteadora dos processos educativos da instituição de ensino pesquisada.

\section{Fundamentação}


A Declaração Universal dos Direitos Humanos adotada pela Organização das Nações Unidas, ONU, em 10 de dezembro de 1948, expressa a universalidade, interdependência, indivisibilidade e inter-relação dos direitos humanos. Diante dessa concepção, ñodos os seres humanos nascem livres e iguais em dignidade e direitos.ò No entanto, em diferentes partes do mundo, os princípios da igualdade e não discriminação tendem a ser violados em razão da diversidade das manifestações humanas, no âmbito cultural, étnico, sexual (ONU,2014).

No âmbito da diversidade sexual tais violações, desde o início de 1990, são registradas pelos mecanismos de direitos humanos das ONU. O debate em torno do tema é desenvolvido mundialmente pela ONU e visa conscientização para a igualdade de direitos a lésbicas, gays, homossexuais e transexuais. Em 2006 a Comissão Internacional de Juristas e o Serviço Internacional de Direitos Humanos, em nome de uma coalizão de organizações de direitos humanos, desenvolveram um projeto com o objetivo de desenvolver um conjunto de princípios jurídicos internacionais sobre a aplicação da legislação internacional às violações de direitos humanos com base na orientação sexual e identidade de gênero, no sentido de dar mais clareza e coerência às obrigações de direitos humanos dos Estados. $O$ projeto foi aprovado por unanimidade e originou o documento, intitulado Princípios de Yogyakarta sobre a Aplicação da Legislação Internacional de Direitos Humanos em relação à Orientação Sexual e Identidade de Gênero. Os Princípios de Yogyakarta afirmam normas jurídicas internacionais vinculantes, que devem ser cumpridas por todos os Estados. Os Princípios prometem um futuro diferente, onde todas as pessoas, nascidas livres e iguais em dignidade e prerrogativas, possam usufruir de seus direitos, que são natos e preciosos (PRINCÍPIOS DE YOGYAKARTA, 2007).

Em 2011 no plenário da ONU, foi aprovada a resolução, № 1719 intitulada, Direitos Humanos, Orientação Sexual e Identidade de Gênero. Em 2012 a ONU lança Campanha ñivres \& Iguaisò acompanhada de uma cartilha com o objetivo de orientar governos e sociedade civil sobre direitos de comunidade LGBT. No Brasil, em 2013, a publicação recebeu o título Nascidos livres e iguais - Orientação Sexual e Identidade de Gênero no Regime Internacional de Direitos Humanos, centra-se em cinco obrigações dos Estados: proteger contra violência homofóbica; prevenir a tortura; descriminalizar a homossexualidade; proibir a discriminação; e defender liberdades civis (UNAIDS BRASIL, 2013).

Em 26 de setembro de 2014, o Conselho de Direitos Humanos da ONU adotou a resolução no 1719 cujo objetivo é compartilhar boas práticas e maneiras de superar a violência e a discriminação na aplicação do direito internacional dos direitos humanos e das normas existentes. O Brasil, um dos países que apresentou o projeto de resolução destacou 
a importância de combater a violência e a discriminação por orientação sexual e identidade de gênero (ONU, 2014).

\subsection{Políticas públicas para a população LGBT}

O acesso e a promoção da não discriminação por orientação sexual visando, entre outros objetivos, o Direito à Educação e ao Trabalho, estabeleceu-se no Brasil, por meio de uma política veiculada pelo Conselho Nacional de Combate à Discriminação intitulada Brasil Sem Homofobia Programa de Combate à Violência e à Discriminação contra LGBT e de Promoção da Cidadania Homossexual (MINISTÉRIO DA SAÚDE, 2004). Segundo essa política os Sistemas de Ensino devem fomentar e apoiar curso de formação inicial e continuada de professores na área da sexualidade; formar equipes multidisciplinares para avaliação dos livros didáticos, de modo a eliminar aspectos discriminatórios por orientação sexual e a superação da homofobia; estimular a produção de materiais educativos (filmes, vídeos e publicações) sobre orientação sexual e superação da homofobia; apoiar e divulgar a produção de materiais específicos para a formação de professores; divulgar as informações científicas sobre sexualidade humana; estimular a pesquisa e a difusão de conhecimentos que contribuam para o combate à violência e à discriminação de LGBT (MINISTÉRIO DA SAÚDE, 2004).

No ambiente de trabalho as ações visam articular, em parceria, com o Ministério Público do Trabalho, a implantação de políticas de combate à discriminação a gays, lésbicas e travestis no desenvolvimento de programa de sensibilização de gestores públicos. Além disso, deve apoiar e fortalecer a rede de Núcleos de Combate à Discriminação no Ambiente de Trabalho das Delegacias Regionais do Ministério do Trabalho e Emprego, fiscalização do trabalho, acesso ao emprego, trabalho e renda (MINISTÉRIO DA SAÚDE, 2004).

Em 2013, o Instituto Ethos promove o debate estimulando as empresas a adotar ações para a construção de um mercado de trabalho que respeite e promova os direitos humanos em geral e os direitos LGBT em particular. A publicação denominada $O$ Compromisso das Empresas com os Direitos Humanos LGBT ï oferece Orientações para o Mundo Empresarial em Ações Voltadas a Lésbicas, Gays, Bissexuais, Travestis e Transexuais, no âmbito do Grupo de Empresas e Direitos Humanos (ETHOS, 2013).

Em 2014 a cultura de inclusão nas empresas é incentivada mediante a publicação do projeto r̃ Construindo a igualdade de oportunidades no mundo do trabalho: combatendo a homo-lesbo-transfobiaò que oferece diretrizes para a promoção dos direitos humanos de pessoas LGBT no mundo do trabalho. O documento é fruto de uma construção conjunta entre organismos da ONU Programa das Nações Unidas para o Desenvolvimento (PNUD, 2014), Organização Internacional do Trabalho (OIT, 2014) e o Programa Conjunto das Nações Unidas sobre HIV/Aids (UNAIDS, 2014) além de representantes de empregadores, trabalhadores, governo, sindicatos e movimentos sociais ligados aos temas LGBT e 
HIV/AIDS. Trata-se de um manual contendo casos, apresentando sugestões e orientações baseadas em procedimentos simples, exigindo, no entanto, comprometimento efetivo com o tema da igualdade de oportunidades e de tratamento. É sugerida a vinculação do emprego do conteúdo às estratégias de gestão de pessoas, às ações gerais de valorização da diversidade ou às ações especificamente relacionadas à valorização da diversidade sexual (PNUD, 2014).

Por outro lado, algumas pesquisas realizadas na academia, tais como de Limongi França e Mecchi (2006), de Garcia e Souza (2010) e de Silva e Carrieri (2012) abordam o tema no âmbito de organizações privadas. Nestes trabalhos a diversidade sexual mostra-se cada vez mais explícita nas organizações, porém as políticas de acolhimento sem reservas ao profissional LGBT, ainda são incipientes. Salientam Baumgardt (2010), Almeida e Martins (2013) aspectos legais e práticas discriminatórias na área trabalhista que estão mais frequentes no judiciário brasileiro. Enfatizam Souza; Siqueira, Ferreira e Zauli-Fellows (2006) a necessidade de uma agenda de pesquisa abordando o tema no mundo do trabalho.

Além disso, há pesquisas, divulgadas na mídia, realizadas por entidades como a Associação Brasileira de Recursos Humanos, ABRH (2015). Constatou-se que as organizações não difundem práticas relativas ao quesito respeito aos trabalhadores LBGT apresentando fracas ações efetivas contra o preconceito. Outra pesquisa, intitulada Demitindo Preconceitos, (SANTOCAOS, 2015), realizada com o grupo LGBT, envolveu 230 entrevistados. Verificou-se que $47 \%$ declaram sua orientação sexual, $90 \%$ contam para os colegas, $32 \%$ para algum superior e apenas $2 \%$ conversam com o gestor de Recursos Humanos. Entre os motivos para não se declarar, estão o medo de ser demitido ou de ser discriminado. Além disso, 40\% afirmam que já sofreram discriminação por orientação sexual no trabalho. A pesquisa aponta situações como fofocas, piadas sem consentimento, assédio moral e exposição ou afastamento de colegas (EXAME, 2015).

\subsection{Gestão de Pessoas nas Organizações}

Gestão de pessoas é a maneira pela qual uma organização orienta o comportamento humano no trabalho. Para isso elabora princípios, estratégias, políticas e práticas ou processos de gestão. Os gestores adotam tais diretrizes para atuar junto às pessoas que trabalham na organização. O modelo é influenciado por fatores externos e internos, tais como contexto sócio-histórico e a características específicas de cada organização (FISCHER, 2002).

Desde o final dos anos 1980, as organizações passam por mudanças em virtude de transformações econômicas, sociais. Para se adequarem ao novo panorama competitivo da globalização da economia e desenvolvimento sustentável, do incremento científico e tecnológico, e dos movimentos sociais as organizações adotam pressupostos estratégicos 
na gestão de pessoas. Estratégia resulta de um processo de decisão (ALBUQUERQUE, 2002). Estratégia é a capacidade de análise do ambiente externo e interno à organização percebendo cenário mercadológico em virtude de forças e fraquezas, ameaças e oportunidades.

Nesse contexto as pessoas são vistas como fonte de vantagem competitiva e o comportamento humano deve alinhar-se às estratégias da organização, salienta Albuquerque (2002). Além disso, um elemento passa a integrar a gestão das pessoas nas organizações é a competência. As organizações devem desenvolver suas competências essenciais. Ĩma competência essencial é um conjunto de habilidades e tecnologias que permite a uma empresa oferecer um determinado benefício aos clientesòassinala Fischer (2002, p.30). Quanto aos trabalhadores, estes passam a ser avaliados pelo critério da mobilização dos saberes, saber, conhecimentos; saber-fazer, experiência; e o saber-ser relativo ao saber comportamental, em situação de trabalho (ZARIFIAN, 2001, 2003). A principal tarefa da gestão de pessoas é desenvolver e estimular as competências humanas necessárias para que as competências organizacionais da empresa se viabilizem, explica Fischer (2002).

Integrado à estratégia encontra-se o recrutamento e seleção, meio pelo qual as pessoas ingressam na organização (DUTRA, 2009). Recrutamento e seleção é um processo destinado ao preenchimento das vagas em aberto, com candidatos que apresentem características e competências pessoais adequadas ao perfil profissional estabelecido pela empresa contratante. Cada organização estabelece um rol de competências que são importantes para o alcance dos objetivos organizacionais (LE BOTERF, 2003).

\subsection{O ensino de Gestão de Pessoas com foco na diversidade}

Embora o fator r̃diversidadeòdeva ser contemplado em todos os níveis da educação, em todos os espaços escolares e em várias disciplinas, é na de gestão de pessoas que ele se encontra mais presente. Isto é, uma disciplina que prepara futuros gestores no trato dos aspectos humanos no trabalho sob várias perspectivas, desde o ingresso de um indivíduo em uma organização até a sua saída, incluindo ainda fatores relativos à saúde dos trabalhadores. Nessa perspectiva, o fenômeno da diversidade é contemplado em todos os âmbitos, onde o docente não ensina apenas conteúdos, mas principalmente atitudes. 0 professor dessa disciplina tem uma responsabilidade ainda maior em explorar com mais propriedade a diversidade para formação de futuros gestores. Para Cifali (2012), Tardif e Lessard (2005) o trabalho docente, é uma profissão humana e de interações, caracterizada pela dimensão relacional e afetiva entre o professor e o estudante que tem necessidade de aprender. O professor, destacam Tardif e Lessard (2005), trabalha com, para e sobre o humano. No caso da disciplina de gestão de pessoas, cabe ainda ao professor ensinar aos educandos a lidar com os aspectos humanos no ambiente organizacional. 
Para que o docente possa explorar o conteúdo relativo à diversidade, sobretudo a diversidade sexual com mais propriedade, o desenvolvimento de competências voltadas para o autoconhecimento, aos próprios valores e preconceitos, se fazem necessários. 0 educador é um formador de opiniões em potencial, prepara futuros profissionais e sua prática docente pode influenciar as atitudes e o comportamento dos educandos. Por isso a importância de uma reflexão constante de sua prática, como afirma Freire (1991, p. 58) m̃inguém nasce educador ou marcado para ser educador. A gente se faz educador, a gente se forma educador, permanentemente na prática e na reflexão sobre a prática.ò

\section{Metodologia}

Trata-se de pesquisa quantitativa de natureza exploratória e descritiva. Segundo Gonçalves e Meirelles (2004) uma pesquisa de abordagem quantitativa busca ainda, identificar o nível de conhecimento, as opiniões, as impressões, os hábitos e os comportamentos, a partir da totalidade das respostas dos indivíduos que na interação com o seu sistema social são influenciados por este. Enquadra-se em pesquisa exploratória, porque visa proporcionar maior familiaridade com o problema com vistas a torná-lo explícito ou a construir hipóteses, pois pretende estudar um fenômeno atual, ainda pouco examinado no Brasil.

Estudos exploratórios fornecem subsídios que auxiliam a descrever os elementos e situações do tema explorado de forma mais precisa. Por outro lado, conforme enfatiza Richardson (1999, p.17), a análise de natureza exploratória busca descobrir as semelhanças entre fenômenos, quando r̃os pressupostos teóricos destes não estão claros, ou são difíceis de encontrar. Nessa situação, é necessário que se faça uma pesquisa não apenas para conhecer o tipo de relação existente, mas, sobretudo para determinar a existência de relação.ò

A investigação caracteriza-se também, como um estudo descritivo, que segundo Malhotra (2006), o caráter descritivo da pesquisa busca em uma população definida determinar um perfil ou uma caracterização e identificar fatores, parâmetros, ou informações que possam ser relacionados por influência ou, mesmo, por diferenciação.

A abordagem metodológica proposta diante do problema de pesquisa é a realização de um estudo de caso, tendo em vista que o objeto principal em estudo se reporta a identificação das percepções de futuros gestores, hoje estudantes dos cursos de Gestão da Faculdade de Políticas Públicas Tancredo Neves ï Campi Belo Horizonte ï Universidade do Estado de Minas Gerais - FaPP/CBH/UEMG. Para Yin (2005, p.32) um estudo de caso é ñma investigação empírica que investiga um fenômeno contemporâneo dentro de seu contexto da vida real, especialmente quando os limites entre o fenômeno e o contexto não 
estão claramente definidosò Segundo Yin (2005) quando se trata de um estudo de caso a definição da unidade de análise deve estar relacionada à maneira como as questões iniciais da pesquisa foram definidas. A unidade de análise é a citada instituição de ensino e os sujeitos de pesquisa, o discente, tecnólogo dos cursos de Gestão Pública, Gestão do Terceiro Setor e Gestão de Recursos Humanos. Os estudos de caso segundo Yin (2005), reúnem numerosas e detalhadas informações acerca de uma situação, podendo utilizar-se de várias técnicas de coleta de dados. Para consecução desta pesquisa, os dados foram coletados por meio de questionário e visaram apreender as percepções de discentes dos cursos de tecnologia em gestão sobre a inclusão da diversidade sexual nas organizações.

Por se tratar de um estudo exploratório, algumas limitações poderão ser observadas na análise dos resultados (YIN, 2005) como a dificuldade de generalizar dados a partir de um único estudo de caso. Mas, o objetivo é explorar e conhecer melhor a área em pesquisa, bem como destacar a importância para o mundo do trabalho.

\subsection{Unidade de Análise: Faculdade de Políticas Públicas Tancredo Neves, FaPP/CBH/UEMG}

A instituição de ensino onde foi realizada a pesquisa é a Universidade do Estado de Minas Gerais, no Campus Belo Horizonte, na Faculdade de Políticas Públicas Tancredo Neves, FaPP/CBH/UEMG, selecionada intencionalmente por facilidade de acesso às informações necessárias para a eficiência deste trabalho.

A Universidade do Estado de Minas Gerais ï UEMG foi criada pelo Art.81 do Ato das Disposições Constitucionais Transitórias da Constituição Mineira de 1989. O parágrafo primeiro do Art.82, do mesmo Ato, proporcionou às fundações educacionais de ensino superior instituída pelo Estado ou com sua colaboração, optar por serem absorvidas como unidades da UEMG. A Faculdade de Políticas Públicas Tancredo Neves, Campus de Belo Horizonte, Universidade do Estado de Minas Gerais ï FaPP/CBH/UEMG ï foi criada pela resolução CONUN/UEMG $n^{\circ}$ 78/2005, de 10 de setembro de 2005, com vistas a contribuir para a consolidação da missão institucional da UEMG relativa ao desenvolvimento de projetos de expansão e diversificação dos cursos oferecidos e, para a ampliação do acesso ao ensino superior no Estado. A FaPP oferece os seguintes cursos de graduação: Tecnologia em Gestão de Recursos Humanos, Tecnologia em Gestão Pública e Tecnologia em Processos Gerenciais (UEMG, 2015).

\subsection{Metodologia de ensino-aprendizagem: a problematização da realidade}

A problematização da realidade acontece por meio da análise de uma situação problema. De acordo com Perrenoud (1999p. 58) ñuma situação problema não é uma situação didática qualquer, pois deve colocar o aprendiz diante de uma série de decisões a serem tomadas para alcançar um objetivo que ele mesmo escolheu ou que the foi proposto 
e até traçadoò Para Bordenave e Pereira (2012, p.38) r̃a solução de um problema consiste em elaborar um novo princípio combinando com princípios já aprendidosò Assim, baseados em princípios aprendidos sobre gestão de pessoas, heteronormatividade e ações afirmativas governamentais o tema da diversidade sexual foi contextualizado. Posteriormente os alunos receberam, em uma folha impressa, a tarefa de analisar a seguinte situação-problema: ñ́Sou gestor (a) em uma organização. Num processo seletivo tenho uma vaga e dois candidatos com perfis adequados. Na entrevista percebo, de alguma forma, que um deles é heterossexual e o outro LGBT. Qual candidato eu admito?ò

Segundo Perrenoud (1999, p.58) uma situação-problema r̃deve oferecer resistência suficiente, que leve o aluno a investir seus conhecimentos anteriores disponíveis, bem como suas representações, de maneira que leve ao seu questionamento e à elaboração de novas ideiasò $A$ análise de 21 afirmativas, manifestando grau de concordância das situações expostas, por meio de uma escala de 5 pontos, de natureza paramétrica ou intervalar, com alternativas que variaram de r̃ Concordo plenamenteò a ñiscordo plenamenteò forneceu dados referentes a práticas e concepções dos alunos sobre as pessoas LGBT e sobre a qual candidato admitiram. Na citada escala, os pontos foram caracterizados pelas medidas (1) ï concordo plenamente, (2) ï concordo e (3) indiferente, (4) discordo, (5) discordo plenamente. O propósito foi identificar o princípio sobre o qual se assenta as práticas dos futuros gestores no tocante à gestão de pessoas na inclusão da diversidade sexual. As afirmativas foram construídas com base no referencial teórico contemplando o princípio da heteronormatividade e diversidade sexual.

\section{Resultados e Discussão}

\subsection{Dados demográficos}

Salienta-se que do total de 120 participantes, alguns não responderam todas as questões. O que sugere certo desconforto frente ao tema colocado. A seguir são apresentados os dados demográficos dos participantes na TABELA 1. 
TABELA 1 - Dados demográficos dos participantes

\begin{tabular}{llcc}
\hline Dados do perfil & Categoria & Quantidade & Percentual \\
\hline Faz parte grupo LGBT & Sim & 13 & $11,37 \%$ \\
\cline { 2 - 4 } Gênero & Não & 102 & $88,7 \%$ \\
\hline \multirow{2}{*}{ Faixa Etária } & Memculino & 50 & $42,4 \%$ \\
\cline { 2 - 4 } & Até 25 anos & 68 & $57,6 \%$ \\
\cline { 2 - 4 } & Entre 26 a 30 anos & 40 & $33,3 \%$ \\
\cline { 2 - 4 } & Entre 31 a 35 anos & 33 & $27,5 \%$ \\
\cline { 2 - 4 } & Entre 36 a 40 & 9 & $10,8 \%$ \\
\cline { 2 - 4 } Experiência & Acima de 41 anos & 15 & $7,5 \%$ \\
\hline Profissional & Menos de 2 anos & 51 & $12,5 \%$ \\
\cline { 2 - 4 } & Entre 2 a 10 anos & 35 & $21,8 \%$ \\
\cline { 2 - 4 } & Entre 11 a 20 anos & 56 & $46,4 \%$ \\
\hline Formação Acadêmica & Primeira Graduação & 64 & $53,3 \%$ \\
\cline { 2 - 4 } & Graduados e Pós-graduados & $51 \%$ \\
\hline
\end{tabular}

Fonte: Os autores (2017)

\subsection{Concepção dos estudantes frente à situação-problema}

A TABELA 2 descreve o tratamento dado pelos estudantes para a seguinte situaçãoproblema colocada pelos pesquisadores: ז́sou gestor (a) em uma organização. Num processo seletivo tenho uma vaga e dois candidatos com perfis adequados. $\mathrm{Na}$ entrevista, percebo, de alguma forma, que um deles é heterossexual e o outro LGBT. Qual candidato eu admito?ò Para apresentar os dados, na TABELA 2, optou-se pela somatória das porcentagens obtida nas alternativas concordo $(C)$ e concordo plenamente $(C P)$, bem como a somatória das alternativas discordo (D) e discordo plenamente (DP), sendo mantidas as respostas గ̃ndiferenteò

Os resultados apontam que o fato de contratar ou não um candidato LGBT não está relacionado à questão da sexualidade. Por meio dos dados coletados, observa-se ainda que, de um modo geral as razões de se contratar um LGBT ou um heterossexual não 
apresentam diferenças. Nessa perspectiva a não contratação de ambos tem muito mais uma relação com as competências exigidas para a função do que pela sexualidade.

TABELA 2: Concepção dos estudantes sobre os candidatos

\begin{tabular}{l|l|l|l}
\hline Motivos para contratar um candidato heterossexual & C+CP & Indiferente & D+DP \\
\hline $\begin{array}{l}\text { Heterossexual é o modelo tradicional de sexualidade, } \\
\text { sou conservador (a). }\end{array}$ & $9,4 \%$ & $14,5 \%$ & $76,1 \%$ \\
\hline $\begin{array}{l}\text { Heterossexual trará/provocará } \\
\text { impactos/problemas no ambiente de trabalho. }\end{array}$ & $12,8 \%$ & $15,4 \%$ & $71,8 \%$ \\
\hline $\begin{array}{l}\text { A vaga é para chão de fábrica onde há muitos homens } \\
\text { ou para o atendimento ao público onde há tendência ao } \\
\text { conservadorismo. }\end{array}$ & $14,5 \%$ & $26,5 \%$ & $59,0 \%$ \\
\hline $\begin{array}{l}\text { Para não provocar polêmica na equipe e no ambiente de } \\
\text { trabalho. }\end{array}$ & $7,7 \%$ & $17,1 \%$ & $75,2 \%$ \\
\hline \begin{tabular}{l} 
Motivos para contratar um candidato LGBT \\
\hline $\begin{array}{l}\text { Porque apresentam tendência ao perfil que supera } \\
\text { obstáculos. }\end{array}$
\end{tabular} & $42,7 \%$ & $38,5 \%$ & $18,8 \%$ \\
\hline $\begin{array}{l}\text { Para combater a discriminação, porque ele é competente } \\
\text { para a função / cargo. }\end{array}$ & $59,0 \%$ & $21,4 \%$ & $19,6 \%$ \\
\hline $\begin{array}{l}\text { Depende do ambiente em que as atividades do cargo } \\
\text { serão desenvolvidas. }\end{array}$ & $13,7 \%$ & $29,1 \%$ & $57,2 \%$ \\
\hline $\begin{array}{l}\text { Depende do ramo de atuação da empresa. } \\
\text { Motivos para não contratar um candidato LGBT }\end{array}$ & $12,0 \%$ & $27,3 \%$ & $60,7 \%$ \\
\hline $\begin{array}{l}\text { A vaga é para chão de fábrica onde há muitos homens } \\
\text { ou para o atendimento ao público onde há tendência ao } \\
\text { conservadorismo. }\end{array}$ & $5,2 \%$ & $17,4 \%$ & $77,4 \%$ \\
\hline $\begin{array}{l}\text { Pessoas LGBT geram conflito, elas são diferentes. } \\
\text { muito eufóricos, falam alto, querem se mostrar. }\end{array}$ & $3,8 \%$ & $15,7 \%$ & $80,6 \%$ \\
\hline
\end{tabular}

Fonte: Os autores (2017)

Conforme se pode observar, os dados mais expressivos da TABELA 2 apontam que 86,9 dos respondentes discordam (D+DP) que a não contratação do candidato LGBT seja justificada pelo temor de retaliação que o gestor pode sofrer frente a sua equipe de trabalho. 
Eles consideram inclusive que a contratação do candidato está relacionada com a competência na função, bem como na possibilidade de reduzir a discriminação no ambiente de trabalho, descrito por $59 \%$.

A contratação de um heterossexual ou LGBT parece não possuir uma relação com o ambiente onde as tarefas serão realizadas e nem com o segmento da empresa, uma vez que $77,4 \%$ discordam que as razões para não contratar um LGBT se devem ao fato de desempenhar as atividades juntos com muitos homens ou no atendimento ao público. Somente 14,5 concordam $(\mathrm{C}+\mathrm{CP})$ que a contratação de um candidato heterossexual, para esse tipo de ambiente, seria mais viável.

Ainda no que diz respeito ao ambiente de trabalho, a maioria dos respondentes, ou seja, $71,8 \%$ não acreditam que a contratação de heterossexual possa reduzir os problemas, provocar menos impactos negativos do que a contratação do LGBT. Apenas 2,6\% concordam que o candidato LGTB possa perturbar o ambiente de trabalho, grande parte $(85,3 \%)$ discorda sobre esse aspecto.

Com relação ao conservadorismo nas empresas que recorre aos métodos tradicionais e que podem reforçar atitudes discriminatórias por meio de processos seletivos que privilegiem a contratação de heterossexuais ao invés de candidatos LBG, os dados revelam que $76,1 \%$ dos estudantes não possuem tendências conservadoras. Isso sugere maior flexibilidade no momento de contratar um candidato LGBT.

\section{Considerações Finais}

Tendo em vista que o processo educativo acontece em vários espaços, não se pode afirmar que o ensino na instituição seja o único fator responsável por modificar ou ampliar a percepção dos estudantes quanto a atitudes discriminatórias. Entretanto, pode-se assegurar que as disciplinas com conteúdo voltado para a diversidade, principalmente a disciplina de gestão de pessoas, contribui para a preparação de futuros gestores no momento de contratar um trabalhador. Os resultados apontam que para os estudantes um processo seletivo depende muito mais das competências necessárias do que da orientação sexual do candidato, apesar de considerarem que o ambiente de trabalho, ainda nos dias atuais, é discriminatório e preconceituoso.

Entende-se que a metodologia de ensino-aprendizagem de problematização da realidade e a solução de problemas exposta neste trabalho permitiu aos alunos a vivência da tomada de decisão frente a um objetivo e a mobilização de saberes para o desenvolvimento de competência. Conclui-se que a adoção de práticas inclusivas por parte dos docentes e dos discentes sugere que os futuros gestores poderão contribuir para a inserção da diversidade sexual nas organizações. Tal fato suscita a redução do preconceito 
e a discriminação, sobretudo nas organizações em que o padrão heteronormativo impede elou restrinja o acesso às pessoas LGBT a determinadas áreas de atuação e nível organizacional.

\section{Agradecimentos}

Agradecemos a todos os nossos discentes cuja contribuição possibilitou este trabaIho. Agradecemos à Pró-Reitoria de Pesquisa e Pós-Graduação ï PROPPG da Universidade do Estado de Minas Gerais ï UEMG cujo Programa Institucional de Apoio à Pesquisa custeou o Projeto de Pesquisa intitulado Desafios e perspectivas para a gestão de pessoas na inclusão da diversidade sexual ï Edital 08/2015 PAPq.

\section{Referências}

ALMEIDA, A.C.; MARTINS, M.A.C. Discriminação por orientação sexual e identidade de gênero no mercado de trabalho: uma visão crítica sobre a jurisprudência trabalhista no Brasil. RIDB, ano 2, №.12, 2013 Disponível em:http://idb-fdul.com acesso em 30/10/2014.

ALBUQUERQUE, L.G. A gestão estratégica de pessoas. In: FLEURY, M. T. L. (Org.) As pessoas na organização. São Paulo: Gente, 2002.

BAUMGARDT D. Os homossexuais e o preconceito no mercado de trabalho frente aos princípios constitucionais. In: Âmbito Jurídico, Rio Grande, XIII, n. 74,mar2010.Disponível:http://www.ambitojuridico.com.br/site/index.php?n link=revista artigo s leitura\&artigo id=7314 Acesso em 22/06/2015. BORDENAVE, J.H.D; PEREIRA, A.M. Estratégias de ensino-aprendizagem.32. ed ï Petrópolis, RJ :Vozes, 2012.

CIFALI, M. Étique et education: l'enseignement une profession de l'humain. Interactions, n.21,2010 (13-27). Disponível em https://mireillecifali.ch/wp/wpcontent/uploads/2012/12/Ethique-et-\%C3\%A9criture.pdf acesso em 05/01/18.

DUTRA, J. S. Gestão de pessoas: modelo, processos, tendências e perspectivas. ï 1. ed. ï 8. reimpr. ï São Paulo : Atlas, 2009.

ETHOS Instituto. O Compromisso das Empresas com os Direitos Humanos LGBT ï Orientações para o Mundo Empresarial em Ações Voltadas a Lésbicas, Gays, Bissexuais, Travestis e Transexuais ï São Paulo: Instituto Ethos, 2013. Disponível em http://www3.ethos.org.br/wp-content/uploads/2013/12/Manual-LGBT Dez 2013.pdf Acesso em 24/06/2015

EXAME. Diversidade sexual é benéfica para empresas. Revista Exame. Disponível em 
http://exame.abril.com.br/negocios/noticias/diversidade-sexual-e-benefica-para-empresas-

diz-pesquisa acesso em 24/06/2015.

FREIRE, P. Pedagogia da Autonomia: saberes necessários à prática educativa.14. ed São Paulo : Editora Paz e Terra, 2000.

FREIRE, P. A educação na cidade. São Paulo: Cortez, 1991.

FISCHER, A. L. Um resgate conceitual e histórico dos modelos de gestão de pessoas. In: FLEURY, M. T. L. (Org.) As pessoas na organização. São Paulo: Gente, 2002.

GARCIA, Agnaldo e SOUZA, Eloisio Moulin de. Sexualidade e Trabalho : Estudo Sobre a discriminação de Homossexuais masculinos no setor bancário. Rev. Adm. Pública [online]. 2010, vol.44, n.6, pp. 1353-1377. ISSN 0034-7612. Disponível em http://www.scielo.br/scielo.php?script=sci arttext\&pid=S0034-76122010000600005. Acesso em 24/06/2015

GONÇALVES, C.A.; MEIRELLES, A.M. Projetos e relatórios de pesquisa em administração. São Paulo: Atlas, 2004.

LE BOTERF,Guy. Desenvolvendo a competência dos profissionais. Tradução de Patrícia Chittoni Ramos Reulliard. Porto Alegre: Artmed, 2003.

MALHOTRA, N.K. Pesquisa de marketing: uma orientação aplicada. 4 ed. Porto Alegre: Bookman, 2006.

MECCHI, C.L.; LIMONGI FRANÇA, A.C.; Diversidade sexual e políticas de gestão de pessoas: um estudo exploratório em três empresas de grande porte. Monografia FEA USP, São Paulo, $2006 \quad$ Disponível em http://www.ead.fea.usp.br/TCC/trabalhos/TCC\%20Cassiano\%20Mecchi.pdf

Acesso em 22/06/2015.

MINISTÉRIO DA SAÚDE. Brasil Sem Homofobia: Programa de combate à violência e à discriminação contra GLTB e promoção da cidadania homossexual. Conselho Nacional de Combate à Discriminação. Brasília : Ministério da Saúde, 2004

ONU. Conselho de direitos humanos da ONU adota resolução pedindo o fim da homofobia. Disponível em http://www.onu.org.br/conselho-de-direitos-humanos-da-onuadota-resolucao-pedindo-fim-da-homofobia/ acesso em 05\11\2014

OIT. Organização Internacional do Trabalho. Discriminação em Matéria de Emprego e Ocupação. Convenção № 111. Disponível em http://www.oit.org.br/node/472.acesso em $\underline{05 / 11 / 2014 .}$

PERRENOUD; P. Construir as competências desde a escola. Trad. Bruno Charles Magne. - Porto Alegre: Artes Médicas Sul, 1999.

PNUD. Manual Promoção dos Direitos Humanos de pessoas LGBT no Mundo do Trabalho Projeto r̃Construindo a igualdade de oportunidades no mundo do trabalho: combatendo a homo-lesbo-transfobiaò Organização Internacional do Trabalho (OIT), Programa das Nações Unidas para o Desenvolvimento (PNUD) e o Programa Conjunto das Nações Unidas 
para o HIV/Aids (UNAIDS), 2014. Disponível em

http://www.pnud.org.br/arquivos/MANUAL completo DireitosHumanosLGBT.pdf

Acesso em 24/06/2015

PRINCÍPIOS DE YOGYAKARTA Princípios sobre a aplicação da legislação internacional de direitos humanos em relação à orientação sexual e identidade de gênero. Disponível em:

http://www.dhnet.org.br/direitos/sos/gays/principios de yogyakarta.pdf, acesso em $11 / 08 / 2015$

RICHARDSON, Roberto. J. Pesquisa social: métodos e técnicas. 3. ed. São Paulo: Atlas, 1999.

SANTOCAOS. Pesquisa Demitindo preconceitos. Disponível em http://www.demitindopreconceitos.com/ http://www.santocaos.com.br/ acesso em 23/06/2015 SIQUEIRA, M. V. S.; FERREIRA, R. C. \& ZAULI-FELLOWS, A. Gays no ambiente de trabaIho: uma agenda de pesquisa. 2006. In Enanpad, 30 Encontro da ANPAD. Disponível em http://www.anpad.org.br/diversos/trabalhos/EnANPAD/enanpad 2006/GPR/2006 GPRA178 2.pdf

SOUZA, Eloisio Moulin de; SILVA, Alfredo Rodrigues Leite; CARRIERI, Alexandre de Pádua. Uma análise sobre as políticas de diversidade promovidas por bancos. Psicol.

Soc. [online]. 2012, vol.24, n.2, pp. 315-326. ISSN 0102-7182. Disponível em http://www.scielo.br/scielo.php?pid=S0102-71822012000200009\&script=sci arttextacesso em 24/06/2015.

TARDIF, M; LESSARD, C. 0 trabalho docente: elementos para uma teoria da docência como profissão de interações humanas. 2a ${ }^{a}$. Ed. RJ: Vozes, 2005.

TERRA. A trajetória contra o preconceito. Disponível em: http://noticias.terra.com.br/brasil/direitos-homossexuais/ acesso em30/10/2014

UEMG ï UNIVERSIDADE DO ESTADO DE MINAS GERAIS disponível em: $\underline{\text { http://uemg.br/ }}$ acesso em 08/08/2015.

UNAIDS BRASIL. Nascidos livres e iguais - Orientação Sexual e Identidade de Gênero no Regime Internacional de Direitos Humanos. Brasília, 2013.

YIN, Robert K. Estudo de caso: planejamento e métodos. 3. ed. Porto Alegre: Bookman, 2005.

ZARIFIAN, P. Objetivo Competência: por uma nova lógica. São Paulo: Atlas, 2001.

ZARIFIAN, P. O modelo da competência: trajetória histórica, desafios atuais e propostas.

Tradução de Eric Roland René Heneaul. São Paulo : Editora Senac, 2003. 